\title{
The seasonal footprinting mechanism in CFSv2: simulation and impact on ENSO prediction
}

\author{
Kathy Pegion $\cdot$ Michael Alexander
}

Received: 14 March 2013/Accepted: 15 July 2013/Published online: 30 July 2013

(C) Springer-Verlag Berlin Heidelberg 2013

\begin{abstract}
The seasonal footprinting mechanism (SFM) is thought to be a pre-cursor to the El Nino Southern Oscillation (ENSO). Fluctuations in the North Pacific Oscillation (NPO) impact the ocean via surface heat fluxes during winter, leaving a sea-surface temperature (SST) "footprint" in the subtropics. This footprint persists through the spring, impacting the tropical Pacific atmosphere-ocean circulation throughout the following year. The simulation of the SFM in the National Centers for Environmental Prediction (NCEP)/Climate Forecast System, version 2 (CFSv2) is likely to have an impact on operational predictions of ENSO and potentially seasonal predictions in the United States associated with ENSO teleconnection patterns. The ability of the CFSv2 to simulate the SFM and the relationship between the SFM and ENSO prediction skill in the NCEP/CFSv2 are investigated. Results indicate that the CFSv2 is able to simulate the basic characteristics of the SFM and its relationship with ENSO, including extratropical sea level pressure anomalies associated with the NPO in the winter, corresponding wind and SST
\end{abstract}

This paper is a contribution to the Topical Collection on Climate Forecast System Version 2 (CFSv2). CFSv2 is a coupled global climate model and was implemented by National Centers for Environmental Prediction (NCEP) in seasonal forecasting operations in March 2011. This Topical Collection is coordinated by Jin Huang, Arun Kumar, Jim Kinter and Annarita Mariotti.

K. Pegion

Cooperative Institute for Research in Environmental Sciences,

University of Colorado, Boulder, CO, USA

\section{K. Pegion $(\varangle) \cdot$ M. Alexander}

Physical Sciences Division, Earth System Research Laboratory,

National Oceanic and Atmospheric Administration,

325 Broadway R/PSD1, Boulder, CO 80305, USA

e-mail: Kathy.Pegion@noaa.gov anomalies that impact the tropics, and the development of ENSO-related SST anomalies the following winter. Although the model is able to predict the correct sign of ENSO associated with the SFM in a composite sense, probabilistic predictions of ENSO following a positive or negative NPO event are generally less reliable than when the NPO is not active.

\section{Introduction}

The seasonal footprinting mechanism (SFM) provides a link between mid-latitude atmospheric internal variability (i.e. the North Pacific Oscillation, NPO) in the winter and tropical Pacific variability 1 year later (Vimont et al. 2001, 2003a, b; Alexander et al. 2010). Fluctuations in the NPO (Walker and Bliss 1932; Rogers 1981), a north-south sea level pressure (SLP) dipole in the north Pacific, impact the ocean via surface heat fluxes during winter, leaving a SST "footprint" in the subtropics. This footprint persists through the spring, impacting the tropical Pacific atmosphere-ocean circulation throughout the following year (Vimont et al. 2001, 2003a, b; Alexander et al. 2010). This mechanism provides a stochastic forcing of the ENSO cycle and can at times initiate an El Nino or La Nina event.

There is evidence that using the SFM as a pre-cursor has the potential to predict ENSO at long lead times (e.g. 6-12 months), across the well-known spring predictability barrier. Vimont et al. (2003b) indicate that the second leading mode from a maximum covariance analysis of winter mid-latitude SLP, summer Northern Hemisphere tropical zonal wind stress, and winter tropical SST 11 months later than the SLP can be used to predict the ENSO cold tongue index 1 year in advance with anomaly correlation skill of 0.46. Anderson (2007) also found that a 
SLP index in the north Pacific could be used to predict JanFeb-Mar Nino3.4 conditions 12-15 months in advance, using a regression model constructed from reanalysis data. Recently, Wang et al. (2012), found that an opposite signed SST anomaly dipole located off the coast of southeastern Asia in the western north Pacific (WNP) during boreal winter is related to ENSO anomalies the following winter, with a maximum correlation of about 0.6 between the WNP anomalies in Dec-Jan-Feb and Nino3.4 the following Dec-Jan-Feb. The WNP is also highly correlated with indices of the SFM, indicating that they are likely related mechanisms. Several studies have also used linear inverse models (LIMs) to predict ENSO-related SSTs (e.g. Penland and Magorian 1993; Penland and Sardeshmukh 1995). The springtime SFM SST pattern closely resembles the LIM "optimal structure", the pattern identified by LIM theory as mostly likely to grow into an ENSO event (Penland and Sardeshmukh 1995; Xue et al. 1997; Thompson and Battisti 2001; Alexander et al. 2008). Specifically, Alexander et al. (2008) demonstrate that a LIM using both tropical and extratropical Pacific SST anomalies as predictors is able to skillfully $(r>0.6)$ predict tropical Pacific SST anomalies up to 1 year in advance when initialized in winter. While these studies have indicated a potential for improving long-lead ENSO forecasts, they have been primarily diagnostic in focus.

If ENSO can be described as a linearly stable or damped regime (e.g. Penland and Sardeshmukh 1995; Chang et al. 1996; Moore and Kleeman 1999; Thompson and Battisti 2000, 2001), then the ability of the SFM to stochastically force an ENSO event would require the Tropics to be preconditioned or "set-up" for the SFM to be an effective forcing mechanism (Vimont et al. 2003b). Alexander et al. (2010) demonstrated this using experiments with a coupled ocean-atmosphere model in which the heat flux forcing associated with a negative $2 \sigma$ NPO event (the center of negative SLP anomalies are located to the south of the center of positive SLP anomalies) was used to force the ocean during winter. The forcing was terminated by early spring, and the coupled model was then allowed to evolve freely. They find that the SFM-related heating is more effective at triggering warm events when the tropical Pacific would otherwise tend toward consecutive La Ninas. The negative NPO also appears to be ineffective in generating El Nino events in the winter following one already in progress. These results indicate that a deeper (shallower) thermocline in the tropical Pacific together with a negative NPO is more (less) likely to develop into an El Nino. This is consistent with the observational study of Anderson (2007) who found that the relationship between SLP anomalies associated with the NPO and ENSO-related SST anomalies 1-year later is stronger when heat content anomalies in the western equatorial Pacific 12-18 months before an ENSO event and 6 months prior to the SFM, have opposite sign to the NPO-related SLP anomalies, indicating that a deeper (shallower) thermocline in the western equatorial Pacific together with a negative (positive) NPO is more effective in producing warm (cold) ENSO events.

The idea that the tropical Pacific should be pre-conditioned for the SFM to be an effective forcing mechanism is consistent with the recharge-discharge oscillator paradigm in which the equatorial Pacific thermocline anomalies during El Nino (La Nina) are negatively (positively) tilted, proportional to the wind stress and SST anomalies (Jin 1997a, b; Meinen and McPhaden 2000; Clarke et al. 2007). Sverdrup transport due to the wind stress curl leads to a poleward (equatorward) discharge (recharge) of warm water anomalies, which flatten the thermocline as the wind stress SST anomalies go to zero. Following El Nino events, about 1 year later, this discharge leaves the thermocline anomalously shallow, which leads to a cold SST anomaly due to anomalous easterly winds and development of $\mathrm{La}$ Nina conditions the following year. The same is true for the transition from La Nina to El Nino, but with opposite signs. Based on the recharge-discharge paradigm, it is not surprising that thermocline depth anomalies in the tropical equatorial Pacific are highly correlated $(r>0.5)$ with Nino3.4 and have been used as a predictor of ENSO together with wind stress anomalies and the current state of Nino3.4 with skillful predictions $(\mathrm{r}>0.5)$ out to 10-months (Clarke and Gorder 2003).

Since the SFM appears to be a means by which the NPO can stochastically force the ENSO cycle, the ability of seasonal prediction models to correctly simulate this mechanism is important to improving long-lead ENSO predictions. This study assesses the capability of the National Centers for Environmental Prediction (NCEP), Climate Forecast System, version 2 (CFSv2), the US operational seasonal prediction model, to simulate the SFM and its relationship with ENSO. This study extends the work of Kim et al. (2011), who investigated the extratropical forcing of ENSO and its impact on eastern Pacific and central Pacific ENSO events in the previous version of the NCEP model (CFSv1). Their results indicate that the NPO in the CFSv1 does not extend as far into the Tropics as observed and the coupling in the model does not extend as long as observed. However, our study emphasizes the ability of the CFSv2 to represent the extratropical forcing of ENSO associated with the SFM, rather than the type of ENSO event simulated.

We also investigate the ability of CFSv2 to predict ENSO events based on SFM-related pre-cursors. The assessment of prediction skill provides an important link between previous diagnostic studies indicating the potential for improving ENSO prediction, based on SFM-related 
pre-cursors, and quantification of the reliability of ENSO forecasts using these pre-cursors. Specifically, we focus on the simulation and prediction of ENSO in the CFSv2 based on two pre-cursors: (1) the sea level pressure anomalies located on the southern lobe of the NPO, to identify when the SFM is active, and (2) the thermocline depth in the tropical Pacific, to identify when the tropical Pacific is "set-up" for the SFM to be effective at initiating a particular phase of ENSO.

\section{Data}

\subsection{CFSv2 decadal simulations}

A series of decadal hindcast experiments were undertaken at the Center-for-Ocean-Land-Atmosphere Studies (COLA) with the CFSv2 model. These experiments were initialized on November 1, 2, 3, and 4 for the years 1960, 1980, and 2005. Each experiment was integrated for 30 years. The initial conditions for the atmosphere and land are from the Climate Forecast System Reanalysis (CFSR; Saha et al. 2010). The ocean initial conditions are from the European Center for Medium Range Weather Forecasting, New Ocean Model and ocean data assimilation system (ECMWF/NEMOVAR; Morgensen et al. 2009), interpolated to the CFSv2 grid. Observed, time-varying carbon dioxide was used in these experiments. The total number of years of integration is 360 . These experiments are used to diagnose the ability of the CFSv2 to simulate the SFM and its relationship with ENSO on interannual timescales. Anomalies are calculated by removing the annual cycle determined by averaging over the 360 years for each calendar month.

\subsection{CFSv2 retrospective forecasts}

The NCEP/CFS, version 2 (CFSv2) retrospective forecasts (CFSRR; Saha et al. 2012) are used to assess the skill of the model in predicting ENSO events based on the SFM. These re-forecasts were made by NCEP for lead-times up to ninemonths over the years 1982-2009, with four initializations $(0,6,12,18 \mathrm{Z})$ every 5 days. This results in twenty-four forecast initializations or ensemble members per month, with the exception of the month of November, which has twenty-eight initializations. The model climatology, as a function of month and lead-time, is calculated and removed to determine anomaly fields.

\subsection{Reanalysis and observed datasets}

The COLA decadal simulations are compared with observations-based datasets to assess how well the CFSv2 simulates the SFM and its relationship with ENSO. For sea-level pressure (SLP) and $10 \mathrm{~m}$ surface winds, the NCEP/NCAR Reanalysis (NCEPR1; Kalnay et al. 1996) is used. For the depth of the $15{ }^{\circ} \mathrm{C}$ isotherm, we use the Simple Ocean Data Assimilation (SODA; Carton et al. 2000a, b). For sea surface temperature, we use the Hadley Centre Sea Surface Temperature dataset (HadSST; Rayner et al. 2006). Our observational analyses use the 50-year period of 1958-2007, which is the period of overlap for these datasets.

For our analyses in which we validate the skill of the CFSv2 re-forecasts, CFSR is used for SLP and depth of the $15{ }^{\circ} \mathrm{C}$ isotherm since it is the analysis used to initialize the re-forecasts and was produced using the CFSv2 model (Saha et al. 2010). Sea surface temperatures are validated against the NOAA/Optimal Interpolation SST analysis, version 2 (NOAA/OISSTv2; Reynolds et al. 2002).

\section{The observed and simulated SFM}

\subsection{Comparison between observed and simulated SFM composites}

The SFM is investigated using wintertime sea-level pressure (SLP) anomalies over the North Pacific. Following Anderson (2007), a sea-level pressure index (SLPI) is defined as the normalized sea-level pressure anomalies averaged over $10^{\circ} \mathrm{N}-25^{\circ} \mathrm{N}, 175^{\circ} \mathrm{W}-145^{\circ} \mathrm{W}$. The SLP anomalies in this region are on the southern lobe of the NPO circulation and have been identified as a critical region for impacting the tropical Pacific (Anderson 2003; Alexander et al. 2008). This index was also used by Deser et al. (2012) to evaluate the simulation of the SFM in the National Center for Atmospheric Research (NCAR), Community Climate System Model, version 4 (CCSM4).

Composite SLP, SST, and 10-meter winds from NCEPR 1 are calculated for all cases where the SLPI is less (greater) than minus (plus) one standard deviation, corresponding to the negative (positive) phase of the NPO. There are 10 negative and 9 positive cases in the NCEPR 1 data for the period 1958-2007 (Fig. 1). The evolution of the SLP, wind, SST, and depth of the $15{ }^{\circ} \mathrm{C}$ isotherm (Z15) fields are consistent with the SFM hypothesis: the negative phase of the NPO, as indicated by a north-south dipole in sea level pressure anomalies in the winter, (Fig. 1, upper left) induces westerly wind anomalies in the subtropical Pacific, which oppose the trades (Fig. 1, upper right) and reduce the heat flux (not shown) leading to a warm subtropical SST "footprint" which persists throughout the spring (Fig. 1a, b; Vimont et al. 2001, 2003a, b). Enhanced westerly wind anomalies in the deep tropics during the spring and summer (Fig. 1 right, middle panels) induce a 


\section{SLPI Neg-PøS}
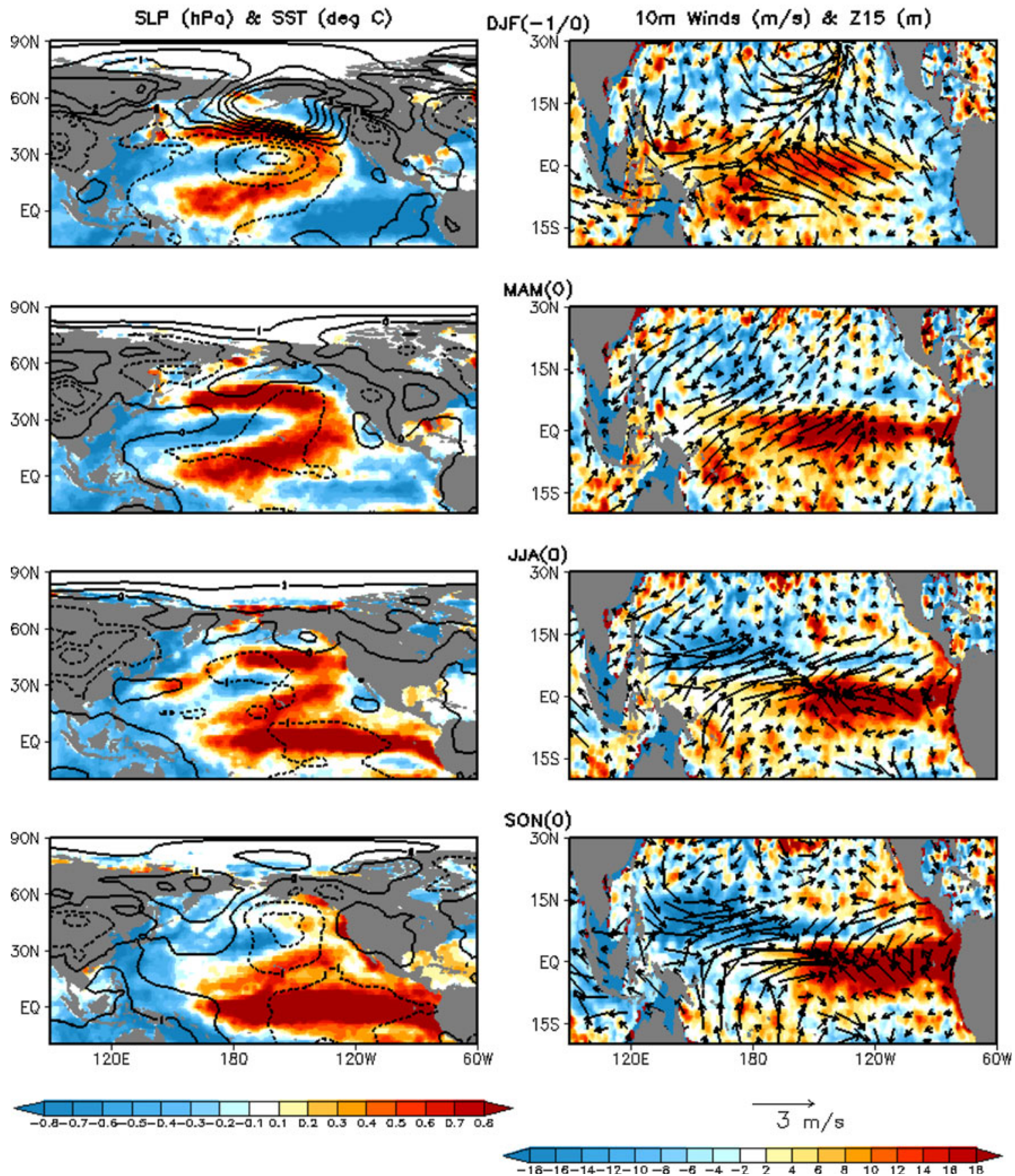

Fig. 1 Seasonal composites of negative minus positive SLPI cases for NCEPR1 SLP (hPa, contours with interval of $1 \mathrm{hPa}$ ) and Hadley Center SST $\left({ }^{\circ} \mathrm{C}\right.$, shaded) (left) and NCEPR1/10 $\mathrm{m}$ winds $(\mathrm{m} / \mathrm{s}$,

downwelling Kelvin wave, leading to warm SST anomalies in the central and eastern tropical Pacific (Fig. 1, bottom left). The reverse occurs for the positive phase of the NPO, leading to ENSO cold, or La Nina conditions.

There are several aspects of the observed composites that differ from the original SFM hypothesis. For example, in the original hypothesis, warm SST anomalies did not

arrows) and SODA depth of the $15{ }^{\circ} \mathrm{C}$ isotherm $(\mathrm{m}$; shaded) (right). Ten negative and nine positive SLPI cases are composited from the years 1958-2007

reach the equator until late spring/summer. However, in the composites, warm SST anomalies are present in the Tropics in DJF (-1/0) and even before, indicating that windevaporation-SST (WES) feedback through the SFM may not be the only mechanism providing a connection between the subtropics and tropics. This is also seen in CCSM4 (Deser et al. 2012). As a result, additional mechanisms 
have been proposed to contribute to the subtropical-tropical connection that occurs in the SFM, including oceanic Rossby waves, that reflect off the western boundary (Alexander et al. 2010) and a trade-wind charging mechanism in which the trade wind variability associated with changes in the NPO leads to an increase in oceanic heat content (Anderson et al. 2013).

Cold SST anomalies are also present in the western subtropical Pacific in the winter and spring. Although not apart of the original SFM hypothesis, these anomalies are consistent with Wang et al. (2012) who found a relationship between the east-west SST anomaly dipole in the subtropical Pacific in winter and ENSO anomalies one-year later.

To assess the ability of the NCEP/CFSv2 model to simulate the SFM, the observed negative minus positive SLPI composites (Fig. 1) are compared with composites from the COLA/CFSv2 decadal simulations (Fig. 2). For these simulations, there is a larger sample than in the observed record, with 59 negative and 54 positive cases. The CFSv2 composites show that the model is able to simulate the features of the SFM with a negative NPO in DJF leading to warm SST anomalies in the tropical Pacific the following winter. However, the winds and thermocline depth anomalies are weak relative to the observations. During JJA, westerly winds in the equatorial Pacific are particularly weak in the model. Consistent with the observations warm SST anomalies are also present in the western Tropical Pacific as early as DJF (-1/0).

\subsection{Relationship between SFM and ENSO indices}

The seasonal footprinting mechanism may provide the potential to improve ENSO predictions at relatively long lead times (e.g. 6-12 months). This long-lead potential for predictability is possible because the NPO occurs in the winter and the SFM connects the wintertime, mid-latitude internal atmospheric dynamics to the tropical Pacific SST several seasons later.

The relationship between the SFM and ENSO is compared between the observations and the CFSv2 simulations (Fig. 3). A study by Yu and Kim (2011) indicates that an El Nino event triggered by extratropical forcing, such as the SFM, is more likely to produce tropical Pacific warming maximized in the central Pacific Ocean (CP), whereas El Nino events triggered by other mechanisms are more likely to have maximum warming in the eastern Pacific (EP). Therefore, we explore the relationship between the SLPI for various ENSO indices spanning the tropical Pacific. These relationships are shown in Fig. 3 beginning with the eastern-most index in the top panel $($ Nino1+2) and moving westward down the page. The regions over which the ENSO indices are calculated are defined in Table 1. The
Nino $1+2$ index is correlated with SLPI at -0.56 . Moving westward, the Nino3, Nino3.4, and Nino4 indices are correlated with SLPI at $-0.58,-0.67$, and -0.68 , respectively. The differences between the correlations are not significant at the $5 \%$ level, indicating that there is little difference in the relationship between ENSO "flavor" and SLPI. Comparison of these relationships with the CFSv2 simulation indicates that it is weaker than in the observations, with correlations of about -0.4 .

There is some evidence that the relationship between tropical Pacific SST and SLPI exhibits decadal variability (Di Lorenzo et al. 2010; Wang et al. 2013; Furtado et al. 2012). As a result, the interannual relationship between the ENSO indices and SLPI may be underestimated, particularly for Nino4. When a high pass filter is applied to remove periods longer than 9 years, the correlation between Nino4 and SLPI increases to -0.75 ; while the correlation with the other indices remains unchanged. However, this change is not significantly different from changes that can be obtained by random chance based on a monte-carlo test developed by Gershunov et al. (2001).

\subsection{Effectiveness of SFM based on state of the tropical pacific}

The existence of the negative (positive) NPO in the winter does not always result in an El Nino (La Nina) by the following winter. There is evidence that the impact of the NPO on development of ENSO conditions through the SFM is also dependent on the state of the tropical Pacific (Anderson 2007; Alexander et al. 2010). This is investigated in the CFSv2 simulations by comparing the relationship between the SLPI and Nino3.4 the following winter, stratified by the depth of the $15^{\circ} \mathrm{C}$ isotherm in the western equatorial Pacific $\left(5^{\circ} \mathrm{S}-5^{\circ} \mathrm{N} ; 160^{\circ}-180^{\circ} \mathrm{E}\right)$, in JunOct 12-18 months prior to an ENSO event, following Anderson (2007) and Deser et al. (2012). This index is referred to as Z15I.

The relationship between SLPI and Nino3.4 is shown in Fig. 4 for the observations (top, left) and CFSv2 (top, right). The values are color coded by whether the sign of the Z15 index is the same (black) or opposite (red) the SLP index, following Deser et al. (2012; see their Fig. 19). In the observations and the CFSv2, the relationship between SLPI and ENSO does not appear to be strongly impacted by the state of the tropical Pacific thermocline. The bottom panels of Fig. 4 show the relationship between DJF SLPI and Z15I for the observations and CFSv2. The relationship between these indices, in both the observations and the model, is much stronger (weaker) when the thermocline anomalies are of the opposite (same) sign as the SLPI anomalies. This supports the idea that the state of the thermocline in the tropical Pacific, together with the sea- 


\section{SPLI Neg-PळS}
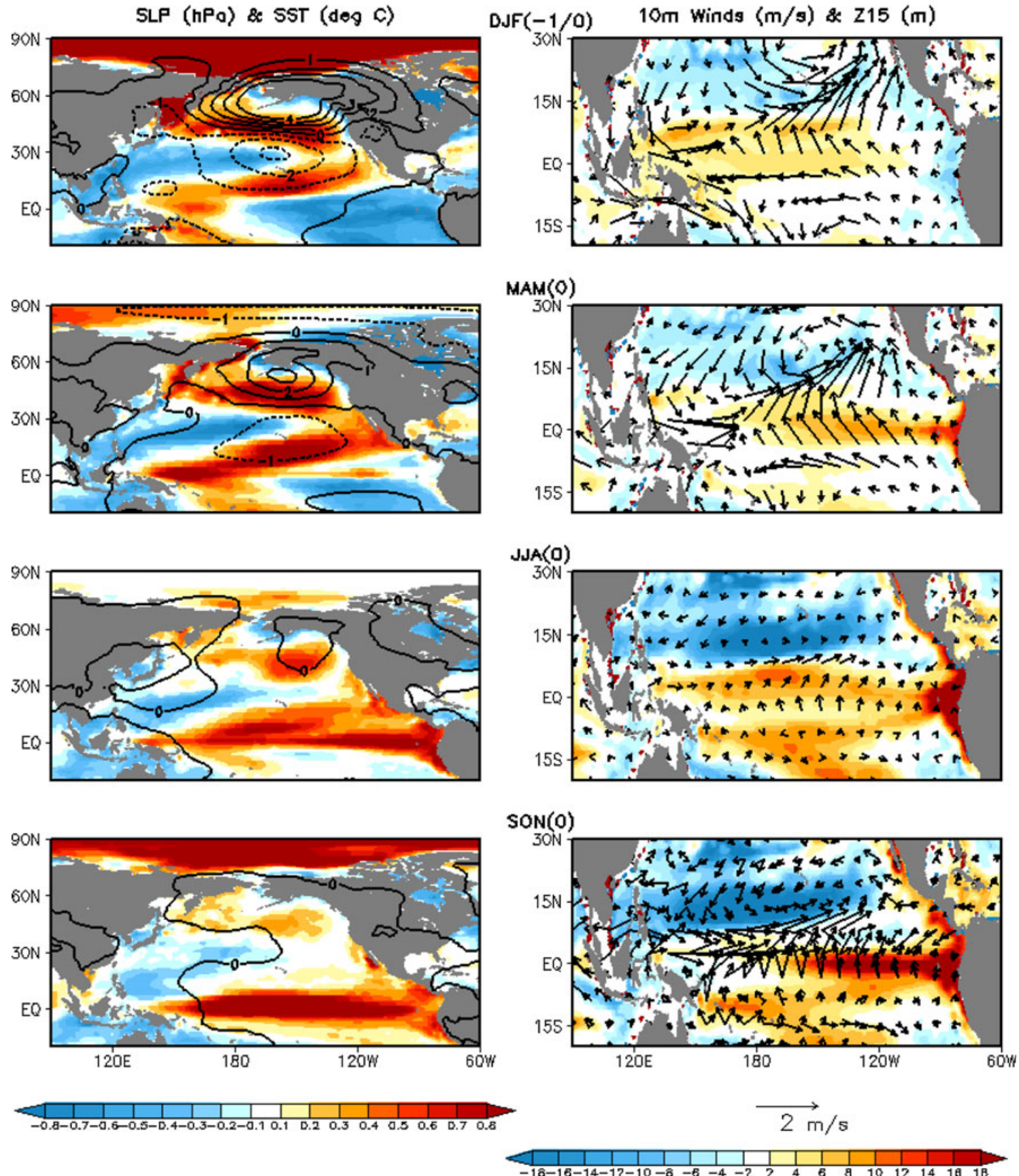

Fig. 2 Seasonal composites of negative minus positive SLPI cases for SLP (hPa, contours with interval of $1 \mathrm{hPa})$ and SST $\left({ }^{\circ} \mathrm{C}\right.$, shaded) (m; shaded) (right) from the CFSv2 decadal simulations. Fifty-nine negative and fifty-four positive SLPI cases are composited over 360 years of model integration

level pressure anomalies on the southern lobe of the NPO, are related to the development of ENSO. The relationships between the SFM, ENSO, and the state of the tropical Pacific for the CFSv2 are weaker than similar calculations for the CCSM4 (Deser et al. 2012). Our observational results are different from those reported in Anderson (2007), likely due to use of a different ocean analysis and

heat content, rather than thermocline depth anomalies for a different set of years (1948-2003).

\subsection{Conditional probabilities}

Not all ENSO events are triggered by the SFM, but when it does occur, it can influence the probability of an ENSO 
Fig. 3 Scatterplots of SLPI and ENSO indices the following winter from east (top) to west (bottom) across the tropical Pacific for observations from NCEPR1 for SLPI and Hadley SST (left) and the CFSv2 simulations (right). Red, blue and black colors indicate $\mathrm{El}$

Nino, La Nina, or neutral conditions, respectively, based on the Nino3.4 index, which is the region used to categorize ENSO events for operational monitoring and prediction. Details of the indices are specified in Table 1 .

Correlations between the indices are indicated in the upper right corner of each panel
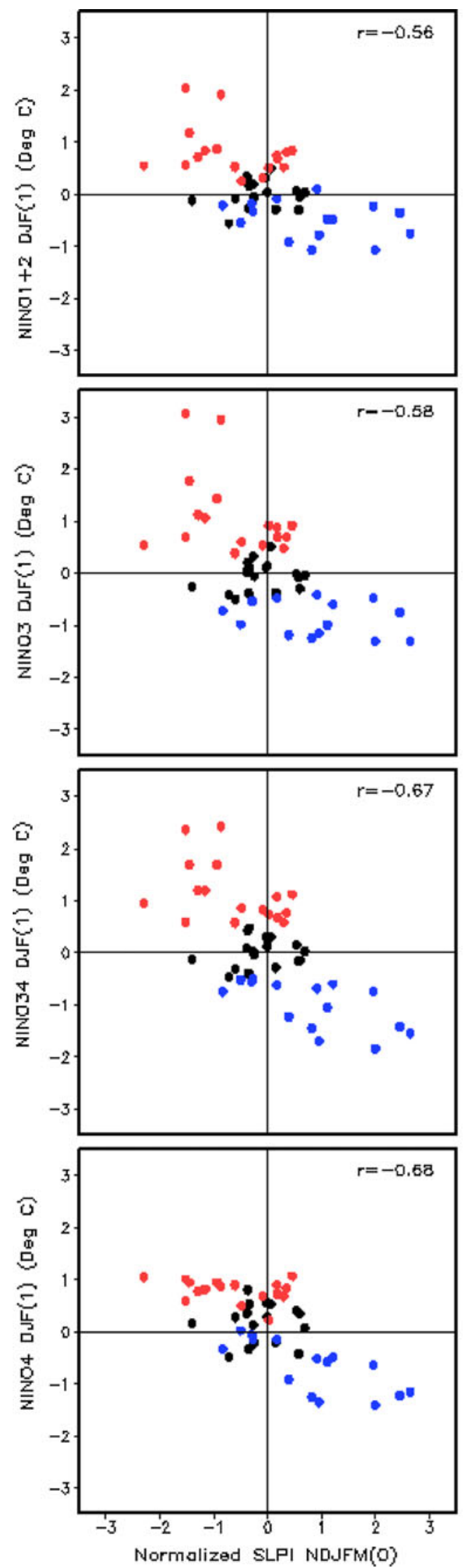
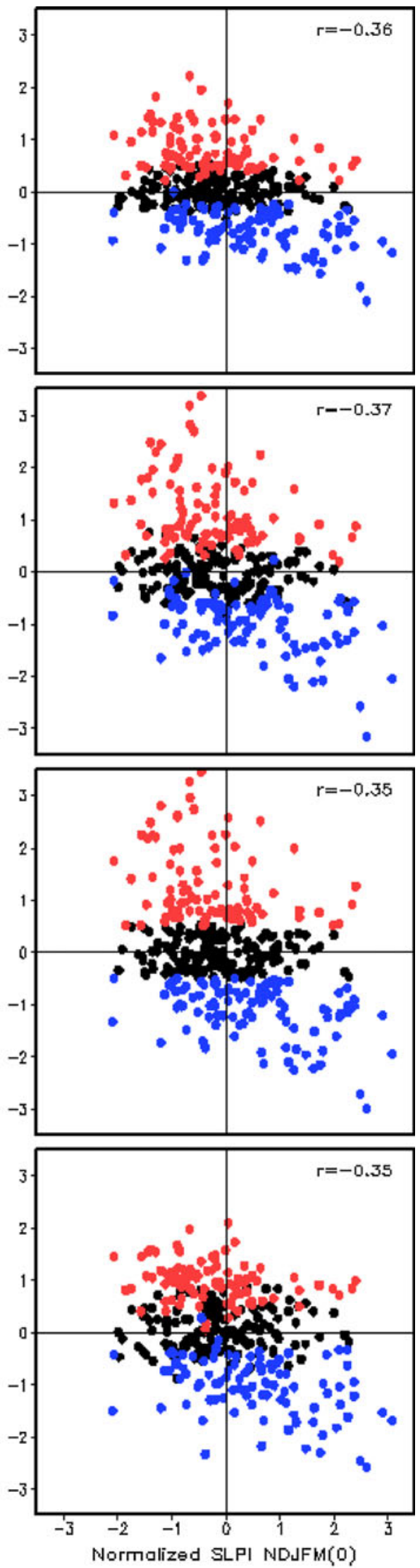
Table 1 Summary of indices used

\begin{tabular}{llll}
\hline Index & Variable & Region & Months \\
\hline SLPI & SLP & $10^{\circ} \mathrm{N}-25^{\circ} \mathrm{N} ; 175^{\circ} \mathrm{W}-145^{\circ} \mathrm{W}$ & Nov-Mar \\
Z15I & Z15 & $5^{\circ} \mathrm{S}-5^{\circ} \mathrm{N} ; 160^{\circ} \mathrm{E}-180^{\circ} \mathrm{E}$ & Jun-Oct \\
Nino3.4 & SST & $5^{\circ} \mathrm{S}-5^{\circ} \mathrm{N} ; 170^{\circ} \mathrm{W}-120^{\circ} \mathrm{W}$ & Dec-Jan \\
Nino1+2 & SST & $0^{\circ} \mathrm{S}-10^{\circ} \mathrm{S} ; 90^{\circ} \mathrm{W}-80^{\circ} \mathrm{W}$ & Dec-Jan \\
Nino3 & SST & $5^{\circ} \mathrm{N}-5^{\circ} \mathrm{S} ; 150^{\circ} \mathrm{W}-90^{\circ} \mathrm{W}$ & Dec-Jan \\
Nino4 & SST & $5^{\circ} \mathrm{N}-5^{\circ} \mathrm{S} ; 160^{\circ} \mathrm{E}-150^{\circ} \mathrm{W}$ & Dec-Jan \\
\hline
\end{tabular}

event occurring. We demonstrate this by calculating conditional probabilities between the SLPI, Z15I, and the Nino3.4 index. The conditional probability between ENSO and SLPI is shown in Fig. 5 (left). The SLPI is divided into three categories (positive, neutral, negative), based on a $\pm 1 \sigma$ threshold. ENSO is also divided into three categories (warm, cold, neutral) based on a $\pm 0.5 \sigma$ threshold. This threshold is selected because it closely corresponds to the $\pm 0.5{ }^{\circ} \mathrm{C}$ threshold commonly used for ENSO. The probability of ENSO being warm, cold, or neutral is 34, 32, and $34 \%$, respectively. In the observations, there is clearly a preference for El Nino (La Nina) events to occur when the SLPI is less (greater) than $-1 \sigma(1 \sigma)$, as $100 \%(>80 \%)$ of La Nina (El Nino) events occurred following a positive (negative) phase of the NPO, which is why the blue, SLPI(+) bar is only present for La Nina. ENSO neutral occurred almost equally regardless of the SLPI category. The CFSv2 indicates similar preferences in sign for El Nino and La Nina for the negative and positive categories of SLPI. However, the probabilities are not nearly as large and ENSO neutral conditions occur in the model more often than El Nino for negative SLPI.

The probabilities for the three ENSO phases are also calculated conditional upon the Z15 index, divided into three categories based on a $\pm 1 \sigma$ threshold. The probabilities of the Z15 index being in the positive, neutral, or negative phase are 18,70 , and $12 \%$, respectively. The probability of the different ENSO phases occurring, conditional upon the Z15I, is not as strong as SLPI, indicating that perhaps Z15I is not a strong ENSO precursor alone, consistent with Fig. 4 and the findings of Anderson (2007). In the observations, there is a preference for El Nino (La Nina) conditions when the Z15I is positive (negative).
Fig. 4 Scatterplots of SLPI and Nino3.4 for observations (upper left) and CFSv2 simulations (upper right) and Z15I and Nino3.4 (bottom). Red points indicate the SLPI and Z15I have opposite signs, while black points indicate that they have the same sign
Obs Nino3.4 va SLP Index (50yra)
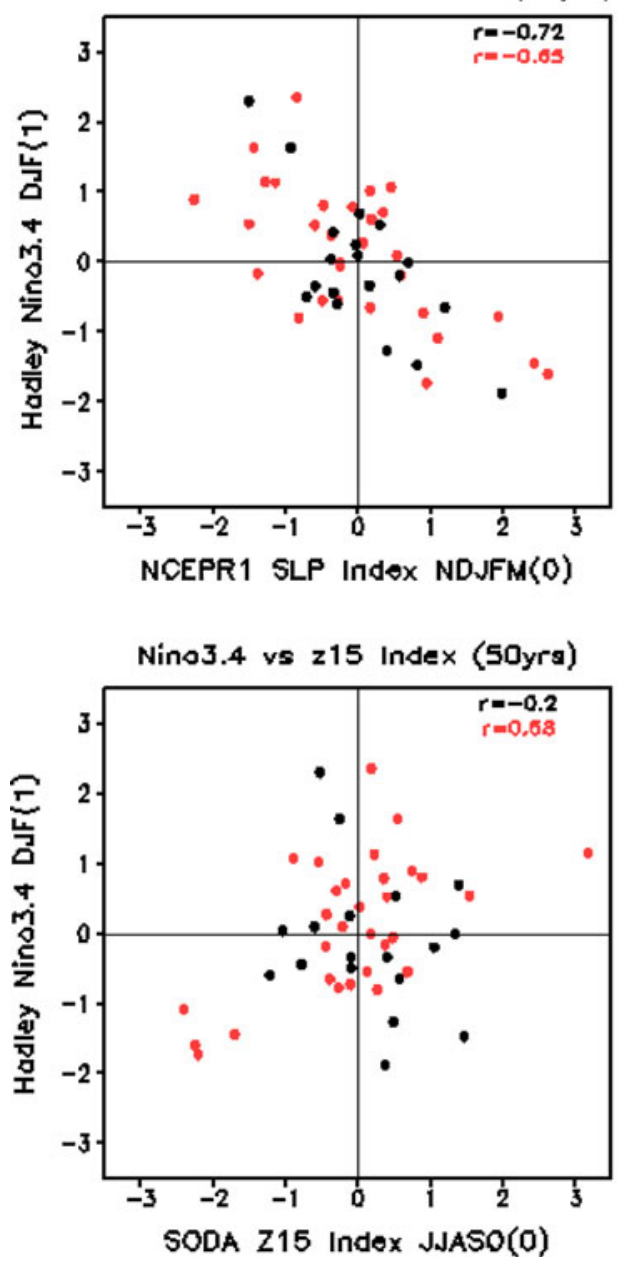

CFSv2 Nino3.4 vs SLP Index (3BOyrs)

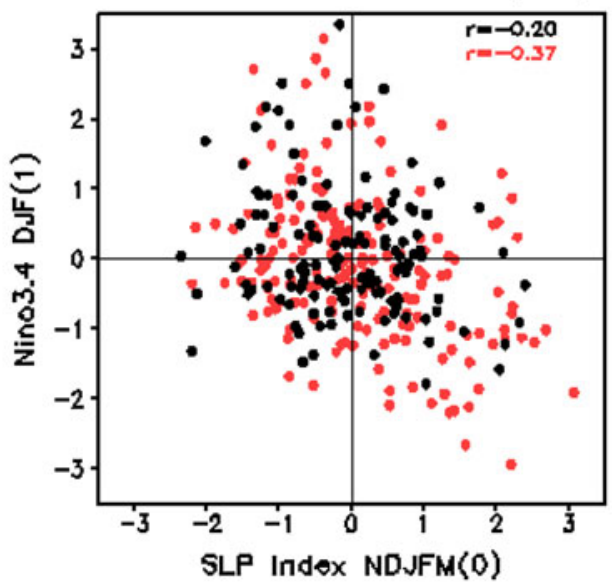

CFSv2 Nino3.4 vs z15 Index (360yrs)

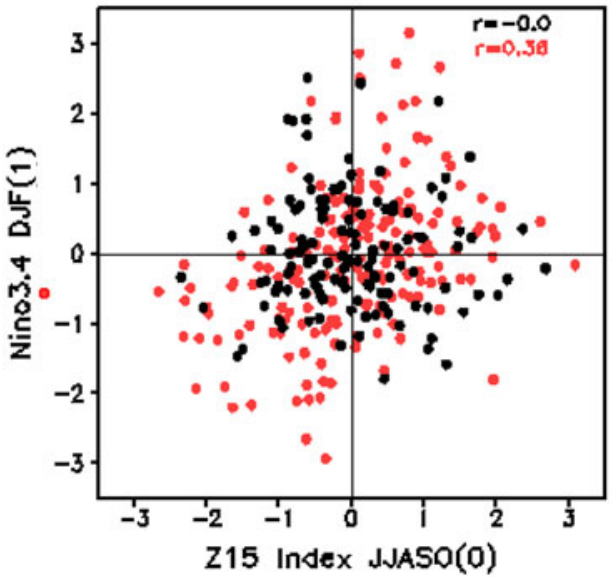


Fig. 5 Probabilities of ENSO events occuring conditional upon SLPI (left) or Z15I (right) for the observations (top) and CFSv2 simulations (bottom). ENSO events are defined as $\pm 0.5 \sigma$ based on Nino3.4, SLPI events are defined as $\pm 1 \sigma$, and Z15I cases are defined as $\pm 1 \sigma$
P(ENSO|SLPI)

$\mathrm{P}(\mathrm{ENSO} \mid \mathrm{Z15})$

OBS (1958-2007)
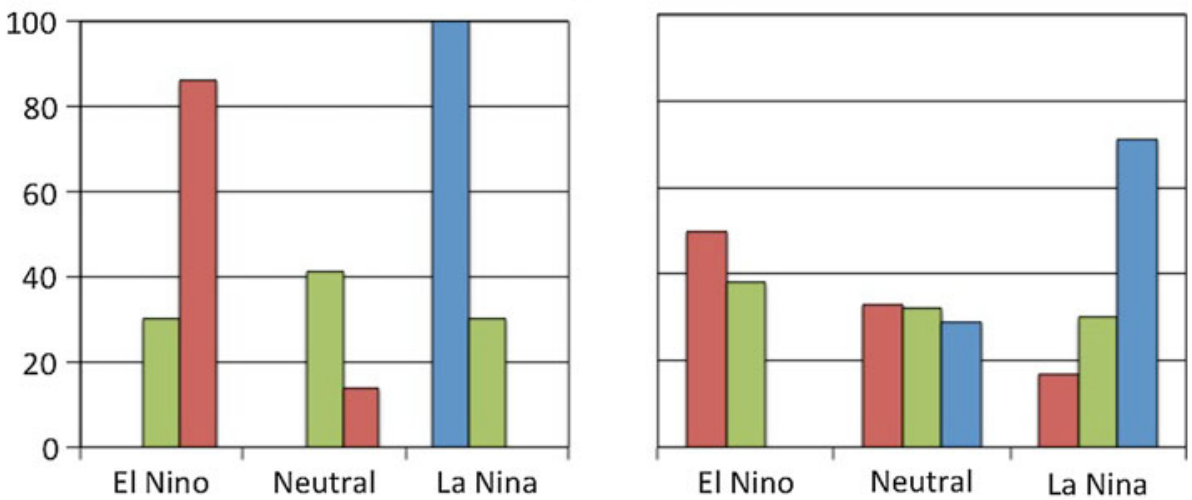

$\mathrm{Z151}(-)$

Z15I(0)

$\mathrm{Z151}(+)$

CFSv2 (360yrs)
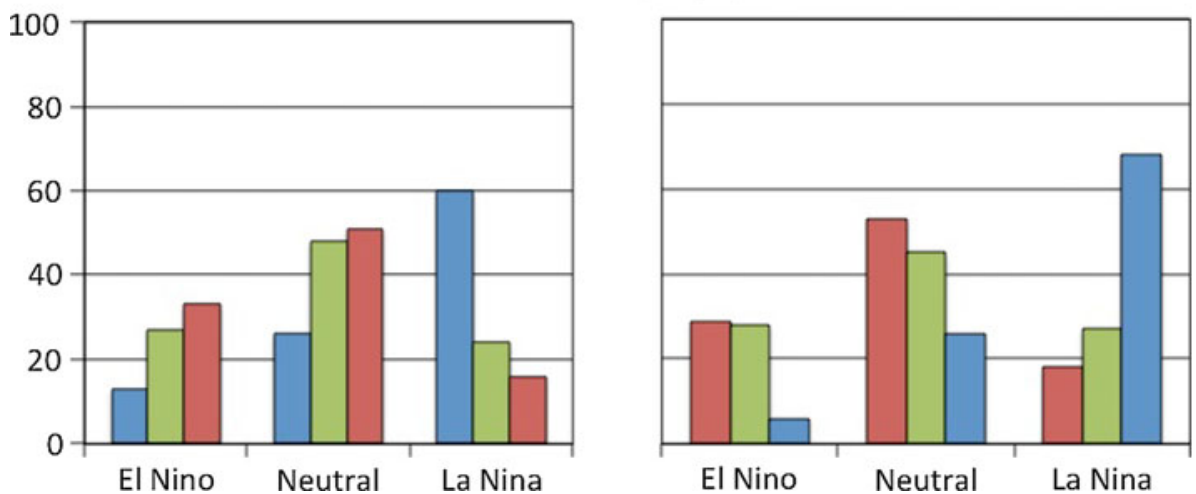

Again, the CFSv2 is able to capture the general preference for ENSO conditions based on the Z15 index, particularly for La Nina. However, the probabilities are not as strong. The model seems to have more difficulty with the probability shift associated with El Nino events indicated by higher probabilities of neutral than El Nino for positive Z15I.

\section{Impact of the SFM on ENSO prediction}

In the previous sections, we assessed the ability of the CFSv2 to simulate the SFM and related ENSO pre-cursors. Next, we investigate the skill of ENSO forecasts from the CFSv2, based on these pre-cursors.

\subsection{Composite relationship}

Since the NPO is the Pacific analog to the North Atlantic Oscillation (NAO) and the NAO is not predictable on seasonal times scales, we do not expect that the model will be able to forecast the NPO at seasonal lead-times (Linkin and Nigam 2008; Feldstein 2000). However, once there is a positive or negative NPO signature in the winter initial conditions, we can quantify the ability of the CFSv2 to predict how the tropical Pacific will evolve and whether an ENSO event will occur. March initial conditions are used to evaluate the forecasts of SST and ENSO indices. This is assessed in terms of SST composites stratified by SLPI for forecasts initialized in March and valid in Sep-Oct-Nov (Fig. 6). Because our sample size for the re-forecasts consist of only 28 years, we lower our threshold for defining SLPI cases to $0.5 \sigma$. In the CFSv2 re-forecasts, there are 5 (9) years with the SLPI greater (less) than (minus) one-half standard deviation and 24 ensemble members in each year. In a composite sense, the CFSv2 forecast produces La Nina (El Nino) conditions for positive (negative) SLPI cases, consistent with the NOAA/OISSTv2 composite for the same dates. The amplitude of La Nina (El Nino) SSTs is larger (weaker) in the model than the 


\section{CFSv2 Composite SST by SLPI Index for SON FCSTs Initiolized in March}
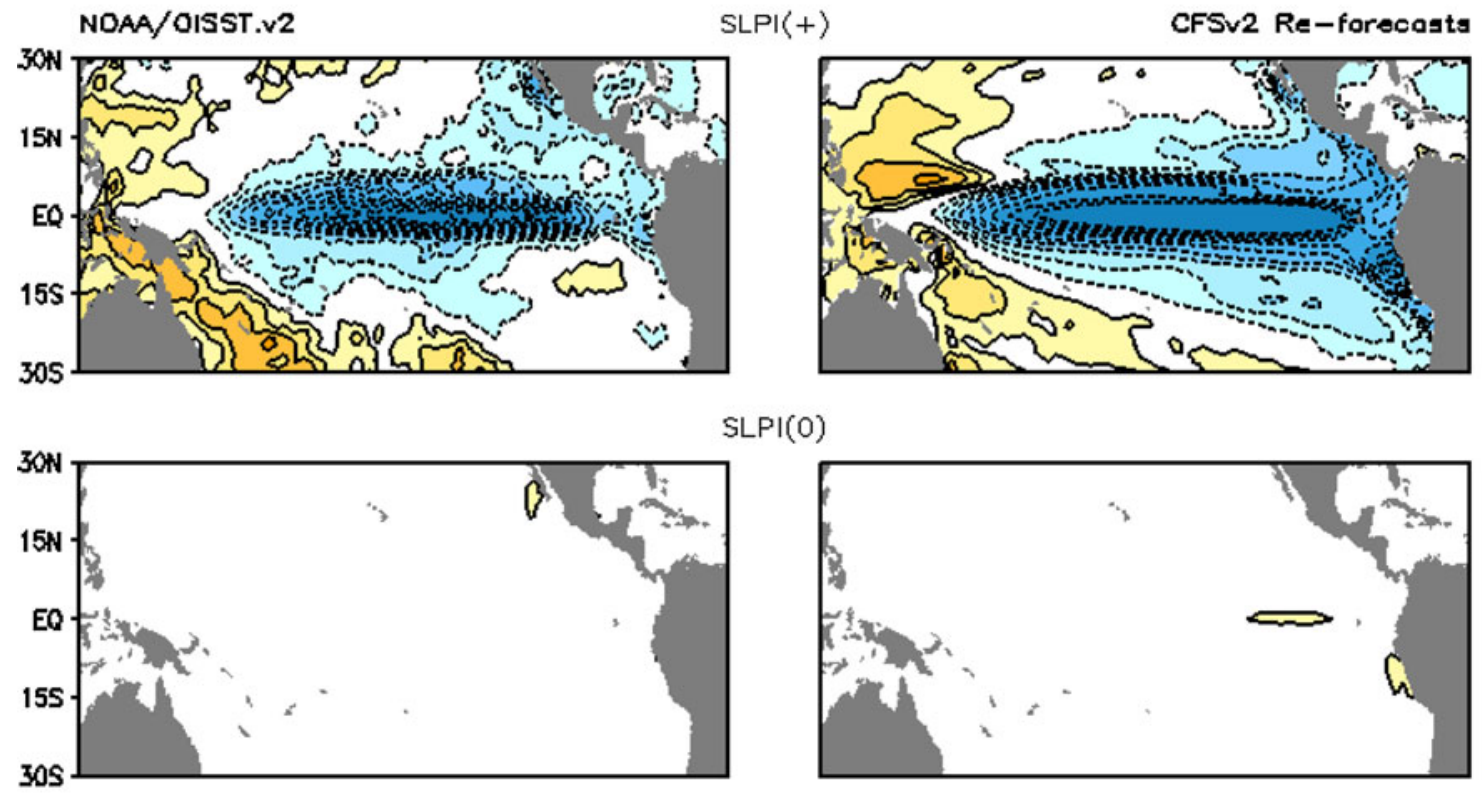

SLPI $\langle-\rangle$
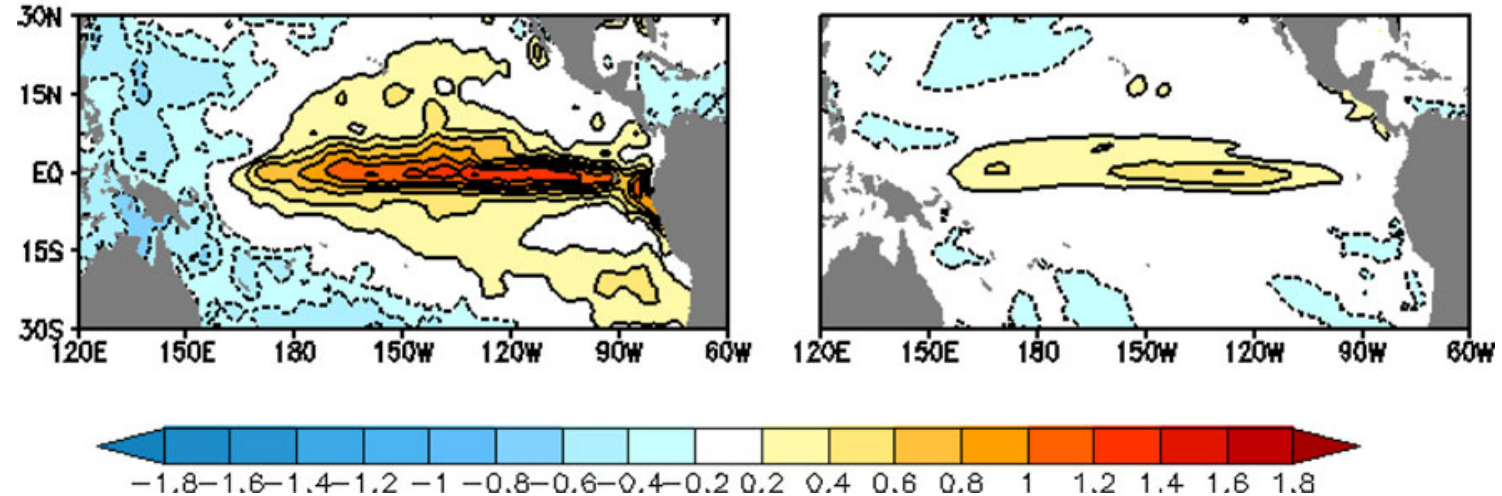

Fig. 6 Composite SSTs from the NOAA/OISST.v2 (left) and CFSv2 re-forecasts initialized in March and valid in Sep-Oct-Nov (right) for SLPI positive, neutral, and negative cases. SLPI cases are defined as $\pm 1 \sigma$ from NCEPR1. There are 5 positive, 14 neutral, and 9 negative SLPI years, each with 24 ensemble members, composited

particularly sensitive to small samples; therefore, we pool the data using forecasts initialized in February, March, and April and valid in Aug-Sep-Oct, Sep-Oct-Nov, and OctNov-Dec, respectively. In the previous analysis, we combined all forecast initializations in a month for a 24-member ensemble. However for this analysis, we use the four initializations for each initial condition day as an ensemble to increase the number of forecasts considered, and calculate the probability of warm, cold, or neutral ENSO events based on these 4-member ensembles. Since we have 4-member ensembles, we choose bins centered at 25,50 , and $75 \%$ for calculating reliability. Probabilities less than $12.5 \%$ or greater than $87.5 \%$ are assigned to the $0 \%$ or $100 \%$ bin.

The reliability diagram and corresponding sharpness histogram, stratified by ENSO phase and SLPI, are shown 

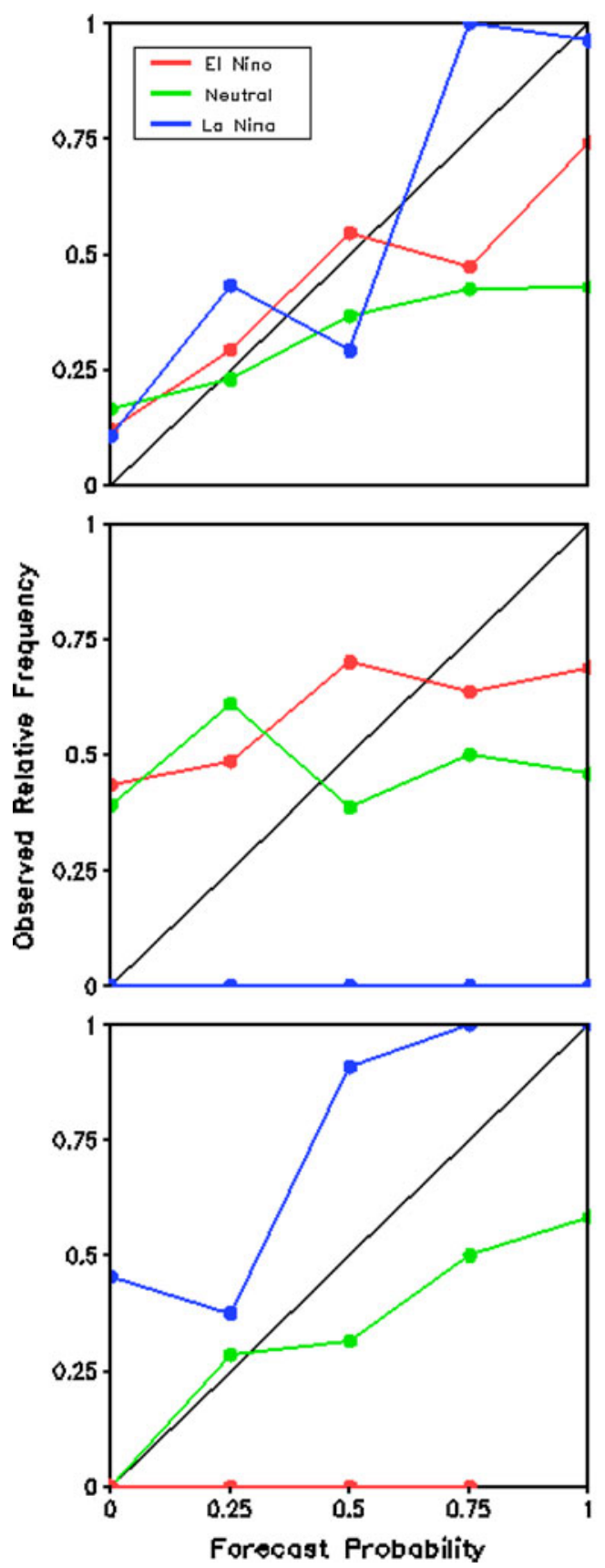

Fig. 7 Reliability diagram (left) and sharpness histograms (right) of CFSv2 re-forecasts of ENSO events for SLPI neutral (top), negative (middle), and positive (bottom) cases. The re-forecasts are four member ensembles initialized throughout the months of Feb, Mar,

in Fig. 7. For perfect reliability, the probability of the forecast and the frequency of occurrence should be the same, indicated by the black line. The top panel shows the reliability and resolution for cases when the SLPI is $-0.5>\sigma<0.5 \sigma$. The slope of the reliability curves and how close they are to perfect reliability, indicate whether the forecasts are reliable. For La Nina events (blue), the slope is positive, indicating that as the forecast probability
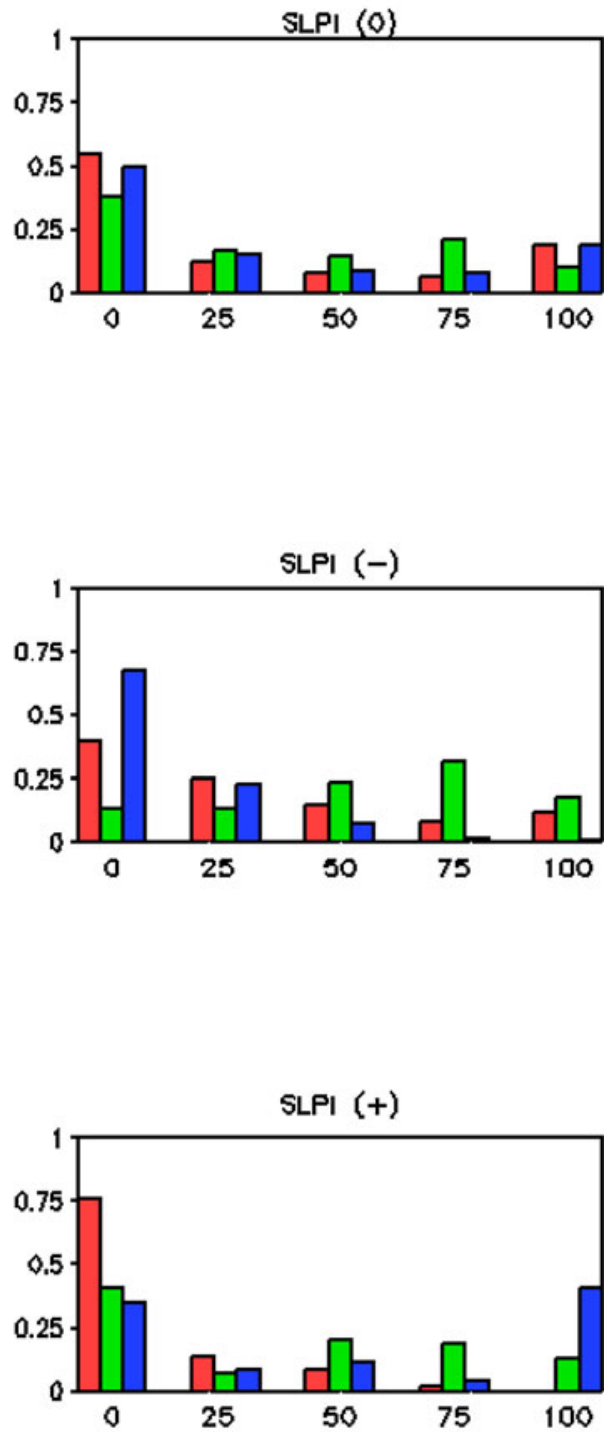

and Apr, and valid in Aug-Sep-Oct, Sep-Oct-Nov, and Oct-NovDec. Red lines and bars indicate El Nino events, blue lines and bars indicate La Nina events, and green lines and bars indicate ENSO neutral

increases, so does the frequency of occurrence, and the line straddles the perfect reliability line, indicating that the forecasts are generally reliable. For neutral and El Nino events, the slope is positive, but less than the diagonal, indicating that the forecasts are overconfident. For example, when the model forecasts $75 \%$ probability of neutral or El Nino events, they occur only about $40-45 \%$ of the time. 
A forecast system that only produces forecasts of climatology would be perfectly reliable, but would not be considered useful. The sharpness of a forecast system indicates its ability to produce forecasts different from climatology. The sharpness histograms indicate the percentage of cases in which the forecasts have probabilities of warm, neutral, or cold ENSO events in each bin. For SLPI neutral cases, the CFSv2 appears to produce a range of probabilities for warm, cold, and neutral ENSO events, but with the highest probabilities in the $0 \%$ bin. Reliability of all ENSO forecasts are similar to the reliability of forecasts for SLPI $(0)$ cases (not shown).

The second two panels (Fig. 7) show the reliability diagram and sharpness histogram for negative and positive SLPI categories. For negative SLPI events, El Nino and neutral events are less reliable than for SLPI neutral cases. For La Nina events, the observed relative probability is zero, but the model predicts anywhere from 0 to $100 \%$, indicating that the forecasts have no reliability. However, the corresponding histogram indicates that the probability of a La Nina forecast being in each bin is largest for the $0 \%$ and decreases to near 0 for the $100 \%$ bin. This indicates that while the model can capture to some extent the direction of the shift in the PDF, it cannot fully resolve it, at least not with the four member ensembles used here. For positive SLPI events, forecasts of El Nino are not reliable, but have the largest (smallest) probability of occurrence in the model in the $0 \%(100 \%)$ bin. Forecasts of La Nina events have slope near 1, indicating that they are reliable, but are biased towards lower probabilities than observed, while forecasts of neutral events are overconfident, similar to the SLPI(0) case. La Nina and neutral forecasts span the full histogram of probabilities. Although the CFSv2 can capture the SFM-related ENSO conditions in a composite sense, meaning that the model can capture the sign of the shift in probability towards a particular phase of ENSO, the reliability analysis indicates that it struggles to correctly represent the forecast probabilities (i.e. the full shape of the PDF) of ENSO associated with the SFM when conditioned on SLP. This is likely due to the fact that the small, four-member, ensemble is likely underdispersed and therefore cannot represent the full PDF. We also tested calculating reliability using the larger, twentyfour member ensemble. However, this greatly reduces the sample size such that there are few forecasts in each bin.

\section{Summary and discussion}

In this study, we investigate the ability of the NCEP/CFSv2 to simulate the seasonal footprinting mechanism and its relationship with ENSO, as well as the skill of the CFSv2 in predicting ENSO, based on this mechanism. The focus is on two aspects of this relationship, which have been identified as potential ENSO pre-cursors in previous studies. We consider a sea level pressure index located on the southern lobe of the NPO to represent the SFM, although this index could include other sources of variability (e.g. quasi-decadal variability; Di Lorenzo et al. 2010; Wang et al. 2013; Furtado et al. 2012), and a thermocline index in the western tropical Pacific to represent the state of the Tropical Pacific and its potential ability to respond to stochastic forcing, such as the NPO, via the seasonal footprinting mechanism.

Composite analysis demonstrates that the CFSv2 is able to simulate the basic aspects of the SFM on average, such as the evolution of the tropical Pacific into El Nino (La Nina) when there is a negative (positive) NPO the previous winter. However, the relationship between the SLP index and ENSO indices across the tropical Pacific is weaker than observed.

We also find that both the observations and the CFSv2 have a stronger relationship between the western tropical Pacific thermocline and ENSO when the SFM provides a "trigger". For example, an El Nino event is more likely to occur in the CFSv2 when the thermocline is deeper in the equatorial western Pacific during the previous winter and a negative NPO event also occurs.

The relationship between the SFM, state of the tropical Pacific, and ENSO is summarized by a conditional probability analysis. The CFSv2 is able to capture the correct direction of shifted probabilities for ENSO events, conditional upon the SFM (indicated by SLPI) and the current state of the tropical Pacific (indicated by Z15I) for La Nina events associated with a positive SLPI and negative Z15I. However, the shift in probabilities is more pronounced in the observations than in the model. The model does not properly capture the relationship between SLPI and Z15I for El Nino events. While higher probabilities of El Nino are associated with negative SLPI and positive Z15I in the observations, ENSO neutral conditions have the highest probabilities in the model, although the model does capture the reduced probability of La Nina for these cases.

The skill of CFSv2 retrospective forecasts is also evaluated, based on these ENSO pre-cursors. Although CFSv2 long-lead forecasts indicate the correct phase of ENSO based on SLPI in a composite sense, ENSO forecasts triggered by the SFM generally have poor reliability. This indicates that there may be potential for improvement in long-lead ENSO forecasts based on the SFM. Future work will investigate the relationship between the SFM and ENSO prediction in the National Multi-model Ensemble.

Acknowledgments We wish to thank Jeff Whitaker for his constructive comments on a previous version on this manuscript. NCEP/ CFSv2 re-forecasts and the CFSR data were obtained from the National Climatic Data Center. 


\section{References}

Alexander MA, Matrosova L, Penland C, Scott JD, Chang P (2008) Forecasting Pacific SSTs: linear inverse model predictions of the PDO. J Clim 21:385-402. doi:10.1175/2007JCLI1849.1

Alexander MA, Vimont D, Chang P, Scott JD (2010) The impact of extratropical atmospheric variability on ENSO: testing the seasonal footprinting mechanism using coupled model experiments. J Clim 23:2885-2901. doi:10.1175/2010JCLI3205.1

Anderson BT (2003) Tropical Pacific sea-surface temperatures and preceeding sea level pressure anomalies in the subtropical North Pacific. J Geophys Res 108:148-227. doi:10.1029/2003JD003 805

Anderson BT (2007) On the joint role of subtropical atmospheric variability and equatorial subsurface heat content anomalies in initiating the onset of ENSO events. J Clim 20:1593-1599. doi:10.1175/JCLI4075.1

Anderson BT, Perez RC, Karspeck A (2013) Triggering of El Nino onset through trade wind-induced charging of the equatorial pacific. Geophy Res Lett 40:1212-1216. doi:10.1002/grl.50200

Carton JA, Chepurin G, Cao X, Giese BS (2000a) A simple ocean data assimilation analysis of the global upper ocean 1950-1995, part 1: methodology. J Phys Oceanogr 30:294-309

Carton JA, Chepurin G, Cao X (2000b) A simple ocean data assimilation analysis of the global upper ocean 1950-1995 part 2: results. J Phys Oceanogr 30:311-326

Chang P, Ji L, Li H, Flugel M (1996) Chaotic dynamics versus stochastic processes in El Nino Southern Oscillation in coupled ocean-atmosphere models. Physica D 98:301-320. doi:10.1016/ 0167-2789(96)00116-9

Clarke AJ, Gorder SV (2003) Improving El Nino prediction using a space-time integration of Indo-Pacific winds and equatorial Pacific upper ocean heat content. Geophys Res Lett 30:1399. doi:10.1029/2002GL016673

Clarke AJ, Gorder SV, Colantuono G (2007) Wind stress Curl and ENSO discharge/recharge in the equatorial Pacific. J Clim 37:1077-1091

Deser C, Phillips AS, Tomas RA, Okumura YM, Alexander MA, Capotondi A, Scott JD, Kwon Y, Ohba M (2012) ENSO and the Pacific decadal variability in the community climate system model version. J Clim 4(25):2622-2651. doi:10.1175/JCLI-D$11-00301.1$

Di Lorenzo E, Cobb KM, Furtado JC, Schneider N, Anderson BT, Bracco A, Alexander MA, Vimont DJ (2010) Central Pacific El Nino and decadal climate change in the North Pacific Ocean. Nat Geosci 3:762-765. doi:10.1038/NGEO984

Feldstein SB (2000) The timescale, power spectra, and climate noise properties of teleconnection patterns. J Clim 13:4430-4440

Furtado JC, Di Lorenzo E, Anderson BT, Schneider N (2012) Linkages between the North Pacific Oscillation and central tropical Pacific SSTs at low frequencies. Clim Dyn 39:2833-2846. doi:10.1007/s00382-011-1245-4

Gershunov A, Schneider N, Barnett T (2001) Low-frequency modulation of the ENSO-Indian monsoon rainfall relationship: signal or noise? J Clim 14:2486-2492

Jin FF (1997a) An equatorial ocean recharge paradigm for ENSO. Part I: conceptual model. J Atmos Sci 54:811-829

Jin FF (1997b) An equatorial ocean recharge paradigm for ENSO. Part II: a stripped-down coupled model. J Atmos Sci 54:830-847

Kalnay E et al (1996) The NCEP/NCAR 40-year reanalysis project. Bull Am Meteor Soc 77:437-470

Kim ST, Yu J-Y, Kumar A, Wang H (2011) Examination of the two types of ENSO in the NCEP CFS model and its extratropical associations. Mon Wea Rev 140:1908-1923
Linkin ME, Nigam S (2008) The North Pacific Oscillation-West Pacific teleconnection pattern: mature-phase structure and winter impacts. J Clim 21:1979-1996

Meinen CS, McPhaden MJ (2000) Observations of warm water volume changes in the equatorial Pacific and their relationship to El Nino and La Nina. J Clim 13:3551-3559

Mogensen K, Balmaseda MA, Weaver AT, Martin M, Vidard A (2009) NEMOVAR: a variational data assimilation system for the NEMO ocean model. ECMWF Newsl 120:17-22

Moore AM, Kleeman R (1999) Stochatic forcing of ENSO by the intraseasonal oscillation. J Clim 12:1199-1220

Murphy AH (1973) A new vector partition of the probability score. J Appl Climatol 12:595-600

Penland C, Magorian T (1993) Prediction of Nino3 sea surface temperatures using linear inverse modeling. J Clim 6:1067-1076

Penland C, Sardeshmukh PD (1995) The optimal growth of tropical sea surface temperature anomalies. J Clim 8:1999-2024

Rayner NA, Brohan P, Parker DE, Folland CK, Kennedy JJ, Vanicek M, Ansell T, Tett SFB (2006) Improved analyses of changes and uncertainties in sea surface temperature measured in situ since the mid-nineteenth century: the HadSST2 data set. J Clim 19:446-469

Reynolds RW, Rayner NA, Smith TM, Stokes DC, Wang W (2002) An improved in situ and satellite SST analysis for climate. J Clim 15:1609-1625

Rogers JC (1981) The north Pacific oscillation. J Climatol 1:39-57. doi:10.1002/joc.3370010106

Saha $\mathrm{S}$ et al (2010) The NCEP climate forecast system reanalysis. Bull Am Meteor Soc 9:1015-1057. doi:10.1175/2010BAMS 3001.1

Saha $S$ et al (2012) The NCEP climate forecast system version 2. J Clim (submitted)

Thompson CJ, Battisti DS (2000) A linear stochastic dynamical model of ENSO. Part 1: model development. J Clim $13: 2818-2832$

Thompson CJ, Battisti DS (2001) A linear stochastic dynamical model of ENSO. Part II: analysis. J Clim 14:445-466

Vimont DJ, Battisti DS, Hirst AC (2001) Footprinting: a seasonal connection between the tropics and mid-latitudes. Geophys Res Lett 28:3923-3926

Vimont DJ, Battisti DS, Hirst AC (2003a) The seasonal footprinting mechanism in the CSIRO general circulation models. J Clim 16:2653-2667

Vimont DJ, Wallace JM, Battisti DS (2003b) The seasonal footprinting mechanism in the pacific: implications for ENSO. J Clim 16:2668-2675

Walker GT, Bliss EW (1932) World weather V. Mem R Meteorol Soc 4(36):53-84

Wang S-Y, L'Heureux ML, Chia H-H (2012) ENSO prediction one year in advance using western North Pacific sea surface temperatures. Geophys Res Lett 39:L05703. doi:10.1029/2012 GL050909

Wang S-Y, L'Heureux ML, Yoon J-H (2013) Are greenhouse gases changing ENSO precursors in the Western North Pacific. J Clim (in press). doi:10.1175/JCLI-D-12-00360.1

Xue Y, Cane MA, Zebiak SE (1997) Predictability of a coupled model of ENSO using singular vector analysis. Part I: optimal growth in seasonal background and ENSO cycles. Mon Wea Rev 125:2043-2056

Yu J-Y, Kim ST (2011) Relationships between extratropical sea level pressure and the Central Pacific and Eastern Pacific types of ENSO. J Clim 24:708-720 